\title{
KPIs in a Management Measurement System Must be Supportive
}

\section{Abbott Haron *}

MBA, Higher Colleges of Technology, Sharjah, Sharjah, UAE

*Corresponding author: Dr. Abbott Haron, MBA, Higher Colleges of Technology, Sharjah, Sharjah, UAE, Tel: +374 10 23-72-61; E-mail: abbottjharon@hotmail.com Received date: December 05, 2014, Accepted date: January 19, 2015, Published date: January 27, 2015

Copyright: (C) 2015 Haron A. This is an open-access article distributed under the terms of the Creative Commons Attribution License, which permits unrestricted use, distribution, and reproduction in any medium, provided the original author and source are credited.

\section{Introduction}

A company's financial goals are highly dependent on the correct firm-wide understanding and interaction in relation to the firm's strategic objectives, which in turn assumes the creation and maintenance of a healthy business-wide environment [1]. This environment must exist, for the organisation to facilitate the support system required for the KPI's to become a reality at all level of the organisation [2].

Smith [3] argues that amassive, widely predominant disconnect exists in most organizations nowadays, at several levels of theoretical abstraction as well as within data flow connections. "Many of our clients view KPI initiatives as an engineering exercise to gather data," says Claus Abildgren, marketing program manager for production and program development for Wonderware. "They don't comprehend the key needs of the business, what are the bits of data that the rest of the business needs to make decisions."

This disconnect is from the bottom-up and from the top-down [3]. Contributing to the problem is the structural flaws in technology infrastructure, in other words, an inability to handle the massive number of applications and quantities of data being generated. "A major company has worked with manufacturers who have over 5,000 point applications in their portfolio," says Colin Masson, research manager for supply networks operations for Boston based AMR Research [3]. This is not even taking into consideration routine data made-up of millions of readings a day and placing that into some business context that has meaning at the upper levels of an organisation.

Lower level metric users might not able to observe how they can influence the firm's bottom line; nonetheless, this does not automatically mean that they are unable to find efficient practices and cost effective methods [4]. The fact that such key drivers are usually located at the lower levels, albeit generally being arranged by the firm's upper levels should be in favor of inclusive and supportive processes whilst discouraging the 'us vs. them' dilemma.

Therefore, only through the complete involvement of the whole system in defining the metrics and applying the measures, which will accurately, endorse a culture of ownership and coordinated actions between the lower and upper levels of an organisation. When this is attained, performance management would have reached its peak, since everyone would have understood what is being measured and most significantly, why [5].

By avoiding misunderstanding and leadings implicity means that, having an observant eye for "duplicative metric creep". Obviously, this does not mean that Altman algorithm does not have its place somewhere else within the company's performance management structure as an early warning method against financial ill health and therefore bankruptcy.

\section{Do You Believe Strassmann's 'Knowledge Management' Metric is an Important One? Why?}

We need to understand that eventually power originates from ownership of resources. The only difference is that until nowadays everybody had it easy. They measured a portion of land, used a clock to measure labor as a type of property, or measured monetary resources. Now we have to start measuring property in terms of knowledge capital, which is as real as property and sometime more valuable [6]

Knowledge management has been with humanity for thousands of years. The subject is only just coming into the spotlight recently, as the case may be, as we attempt to validate further computerization, which would claim to deliver the benefits of improved productivity. Computers have run-out of established economic utility as a competence or output improvement by virtue of the well-known "productivity paradox" which affirms that profitability and computer investments are unrelated [7]. The question has now moved to the topic of knowledge management, which maybe will bail out and validate additional trillions of dollars' worth of expenditure.

In addition, long ago, Strassmann [7] stated that having computers for organizational processes is not what matters; rather it is what people do with those computers. He further argued that the importance of user's motivation and commitment in systems' usage usefulness. He asserts that the availability of KMS (knowledge Management systems) in organizations did not guarantee its use by employees. Therefore, we need to consider the role played by the sociotechnical approach, and the effects of innovative value, norm, organizational cultural value, and KMS features as forecasters and KMS user's independent motivation as arbitrator of KMS deployment.

Furthermore, our research indicates that the importance of the Strassmann's knowledge management' metric is based on the existence of innovative norms in organizations and KMS which, delivers adequate associations or connections amongst knowledge workers and significantly and positively relates to the development of independent motivation towards KMS use. In addition, autonomous motivation to use KMS was found to have considerable influence on KMS usage and reasonably influences the development of competency within the organisation. In conclusion, the actual utilization of KMS was found to be contributing meaningfully to competency development among knowledge workers at all levels most organisations [8].

\section{References}

1. Parmenter D (2002) Winning KPIs. CA Charter. 73: 66-67.

2. Prabhu D, Hegde S (2012) Design and Implementation of Performance Management Systems, KPIs and Responsibility Centers: A Case Study. South Asian J of Manage 19: 121

3. Smith FO (2007) KPIs Made Easy. Control Engineering 54. 
Page 2 of 2

4. Posayanant S, Chareonngam C (2010) Prototype KPIs for rura infrastructure development The practice of sub-district local governments. Int J of Productivity and Performance Manage 9: 717-733.

5. Chakraborty A, Chuan TK (2013) An empirical analysis on Six Sigma implementation in service organisations. Int J of Lean Six Sigma 4: 141-170.

6. Strassmann P (1999) An Interview with Paul Strassmann. (S. Silverstone Interviewer) Knowledge Management Magazine.
7. Strassmann P (1997) The Squandered Computer.

8. Oyefolahan IO, Dominic PD (2013) Knowledge management systems use and competency development among knowledge workers. The journal of information and knowledge management system 43: 482-500. 